\section{TABLE 1. Baseline characteristics}

\begin{tabular}{ll}
\hline Total patient no. & 690 \\
Age, y (range) & $66.7(23-90)$ \\
Male sex, n (\%) & $418(60.6)$ \\
History of cardiovascular & $155(22.5 \%)$ \\
disease & \\
Antithrombotic prophylaxis, & Postoperative UFH, 464 (67.2) \\
n (\%) & Postoperative LMWH, 153 (22.2) \\
& Preoperative LMWH or UFH, 52 (7.5) \\
& Bridging therapy, 5 (0.7) \\
& No prophylaxis, 16 (2.3) \\
Type of cancer, n (\%) & Primary lung cancer, 507 (73.5) \\
& Adenocarcinoma, 51.8\% \\
& Epidermoid, 28.6\% \\
& Anaplastic, 8.0\% \\
& Other, 11.6\% \\
Type of operation, n (\%) & Secondary lung cancer, 183 (26.5) \\
& Pneumectomy, 93 (13.5) \\
& Lobectomy or wedge resection, \\
& 597 (86.5) \\
\hline
\end{tabular}

$U F H$, Unfractionated heparin; $L M W H$, low-molecular-weight heparin.

to PE only in $4(0.6 \%)$ patients, and other causes included septicemia and acute myocardial infarction.

\section{Discussion}

In our chart review we collected data on almost 700 patients undergoing chest surgery for malignant lung disease, and almost $90 \%$ of these patients attended at least 1 follow-up visit. Venous thromboembolic events within 1 month after surgical intervention were uncommon in these patients. Incidence of VTE was lower than pre- viously reported. In a previous study on 77 patients undergoing pulmonary resection, ${ }^{2} 20(26 \%)$ had a venous thromboembolic event (15 deep vein thromboses and 5 PEs) during hospitalization, and in a retrospective study on 1735 patients who underwent lung resection, ${ }^{3} \mathrm{PE}$ was a common fatal postoperative complication, accounting for $15.2 \%$ of postresectional deaths. However, because these studies were carried out between 1975 and 1993, antithrombotic prophylaxis with heparin was rarely used in these patients.

Finally, in a small recent study carried out in 50 patients undergoing lung surgery for cancer, ${ }^{4} \mathrm{PE}$ was detected by means of multislice computed tomographic analysis in $7(14 \%)$ patients. However, only 2 of these patients were symptomatic, and the clinical relevance of this complication is undefined.

In conclusion, the results of our study suggest that symptomatic and fatal PEs are uncommon complications in these patients. Unfractionated heparin and low-molecular-weight heparin seem to be equally effective in reducing venous thromboembolic events also in patients with metastatic disease. Large prospective studies are warranted to confirm our results.

\section{References}

1. Loganathan RS, Stover DE, Shi W, Venkatraman E. Prevalence of COPD in women compared to men around the time of diagnosis of primary lung cancer. Chest. 2006;129:1305-12.

2. Ziomek S, Read RC, Tobler HG, Harrell JE Jr, Gocio JC, Fink LM, et al Thromboembolism in patients undergoing thoracotomy. Ann Thorac Surg. 1993;56:223-6.

3. Kalweit G, Huwer H, Volkmer I, Petzold T, Gams E. Pulmonary embolism: a frequent cause of acute fatality after lung resection. Eur J Cardiothorac Surg. 1996;10:242-6.

4. Daddi G, Milillo G, Lupattelli L, Ragusa M, Lemmi A, Puma F, et al. Postoperative pulmonary embolism detected with multislice computed tomography in lung surgery for cancer. $J$ Thorac Cardiovasc Surg. 2006; 132:197-8.

\title{
Closure of a large tracheoesophageal fistula using AlloDerm
}

\author{
Jang Wen Su, MD, David P. Mason, MD, Sudish C. Murthy, MD, PhD, and Thomas W. Rice, MD, Cleveland, Ohio
}

$\mathrm{T}$ racheoesophageal fistula (TEF) is an uncommon but devastating complication of prolonged intubation. Pressure exerted from the cuff of an endotracheal tube against a rigid nasogastric tube causes tissue necrosis and break-

\footnotetext{
From the Department of Cardiovascular and Thoracic Surgery, Cleveland Clinic Foundation, Cleveland, Ohio.

Received for publication Sept 18, 2007; accepted for publication Nov 20, 2007.

Address for reprints: David P. Mason, MD, 9500 Euclid Avenue, General Thoracic/F24, Cleveland, OH 44195 (E-mail: masond2@ccf.org).

J Thorac Cardiovasc Surg 2008;135:706-7

$0022-5223 / \$ 34.00$

Copyright $\odot 2008$ by The American Association for Thoracic Surgery doi:10.1016/j.jtcvs.2007.11.014
}

down. ${ }^{1}$ Patients typically present with recurrent aspiration pneumonia. Urgent repair of the fistula with tissue interposition is warranted, although this can be challenging in the ventilated patient because of the need for continued positive pressure ventilation and the paucity of healthy, local tissue to fashion the repair. The present study is a case report of a 65-year-old woman in whom a large TEF developed after bilobectomy and who was successfully treated with AlloDerm (LifeCell Corporation, Branchburg, NJ), a commercially available biologic tissue. In this case, AlloDerm was used as a tissue scaffold to reconstruct the defect in the trachea to serve and enhance the integrity of the repair. ${ }^{2,3}$

\section{Clinical Summary}

A 65-year-old woman underwent right middle and lower lobectomy for non-small cell lung carcinoma at an outside hospital. Her postoperative course was marked by adult respiratory distress syndrome and prolonged mechanical ventilation that required tracheostomy. 

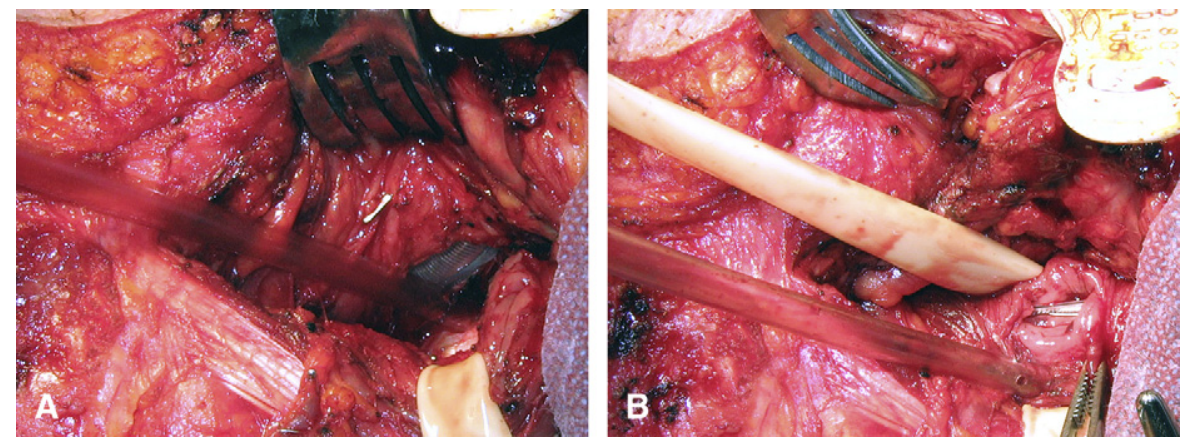

Figure 1. A, Large tracheal defect exposing the tracheostomy tube. B, Esophageal defect and nasogastric tube.
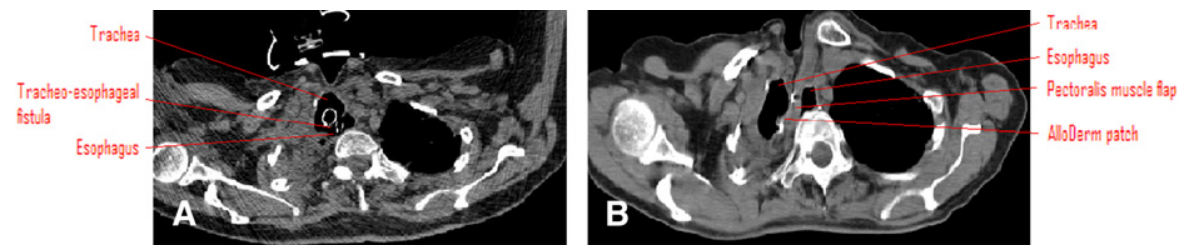

Figure 2. A, Computed tomographic image of a large TEF. B, Follow-up computed tomographic image shows intact tracheal repair with AlloDerm (LifeCell Corporation, Branchburg, NJ) graft. There is no evidence of recurrence of TEF. TEF, tracheoesophageal fistula.

Six weeks post-tracheostomy, recurrent pneumonia and sepsis developed in the patient. Subsequently, the patient underwent bronchoscopy and was diagnosed with TEF. She was transferred to the Cleveland Clinic Foundation for management.

In the operating room, fiberoptic bronchoscopy was performed transnasally and through the patient's tracheal stoma. A 4-cm defect involved the entire width of the membranous airway directly posterior to the stoma. The nasogastric tube was clearly visible along this length and confirmed the diagnosis of TEF. The region of the fistula was 3 tracheal rings distal to the cricoid cartilage on the airway side and $15 \mathrm{~cm}$ from the gums on the esophageal side. An extended length tracheostomy was reinserted.

Given the size of the TEF, primary repair of the trachea was not possible. We elected to use AlloDerm to reconstruct the membranous trachea, close the esophageal defect primarily, and interpose a muscle flap. The airway and esophagus were approached through an oblique left neck incision anterior to the border of the sternocleidomastoid muscle. The esophagus was dissected out, encircled, and separated from the airway. The entire tracheal and esophageal defects were carefully delineated (Figure 1). The esophagus was repaired using interrupted 3-0 Vicryl sutures. A $4 \times 2.5-\mathrm{cm}$ AlloDerm patch was then parachuted down to reconstruct the membranous trachea and secured to the edges of the cartilaginous airway using 3-0 Vicryl sutures. A pectoralis major muscle flap was then mobilized and interposed between the 2 repairs. Postoperatively, the patient had an uneventful recovery and was weaned from the ventilator. On the fifth postoperative day, a flexible bronchoscopy was performed through the stoma. This revealed an intact, well-approximated AlloDerm graft with no evidence of airway narrowing.
The patient was discharged on the 18th postoperative day and decannulated 7 weeks postoperatively in the clinic. Currently, she is tolerating a normal oral diet and doing well at 4 months' follow-up. A follow-up computed tomography scan was performed that demonstrated a widely patent trachea with no residual tracheal defect or fistula (Figure 2).

\section{Discussion}

Secure closure of postintubation TEF is a challenge because of global patient debilitation, inadequacy of local tissue for reconstruction, and an inflamed, infected operative field. ${ }^{4}$ AlloDerm, an acellular dermal matrix derived from donated human skin tissue, has been used in a broad range of tissue reconstruction. Its rigidity and substantial ability to resist infection allowed this repair of a large TEF. Tissue ingrowth appears to prevent shrinkage and stricture. AlloDerm is a useful tool for complex airway reconstructions when options are limited.

\section{References}

1. Dartevelle P, Macchiarini P. Management of acquired tracheo-esophageal fistula. Chest Surg Clin N Am. 1996;6:819-36.

2. Sinha UK, Chang KE, Shih CW. Reconstruction of pharyngeal defect with AlloDerm and sternocleidomastoid muscle flap. Laryngoscope. 2001;111:1910-6.

3. Isch JA, Engum SA, Ruble CA, Davis MM, Grosfeld JL. Patch esophagoplasty using AlloDerm as a tissue scaffold. J Pediatr Surg. 2001;36: 266-8.

4. Daniel Knott P, Lorenz RR, Eliachar I, Murthy SC. Reconstruction of a tracheobronchial tree disruption with bovine pericardium. Interact Cardiovasc Thorac Surg. 2004;3:554-6. 